\title{
1.02
}

\section{O equilíbrio entre 0 individual $e$ o coletivo na busca pela universalidade do Sistema Único de Saúde}

Balancing individual and collective interests in the search of universality in the Brazilian Unified Health System (SUS)

\section{Danielle da Costa Leite Borges}

Advogada, Doutora em Direito e Mestre em Saúde Pública. Rio de Janeiro, Brasil.

\section{Mercedes Schumacher}

Advogada. Pós-graduada em Políticas Públicas. Rio de Janeiro, Brasil.

Resumo: A possibilidade de postulação individual de direitos sociais, especialmente do direito à saúde, trazida pela Constituição de 1988 representa um enorme passo na realização de um sistema universal de saúde. No entanto, o aumento expressivo de demandas individuais relacionadas à prestação do direito à saúde no âmbito do Sistema Único de Saúde (SUS), situação vivida pelo Judiciário Brasileiro nos últimos anos, acaba por gerar conflitos entre o aspecto individual e o coletivo em relação ao sistema de saúde, sendo certo que o aspecto coletivo é essencial no alcance de um sistema público e universal. Diante deste contexto, e usando como exemplo o caso das demandas individuais para obtenção de medicamento e tratamentos no âmbito do SUS, este artigo se propõe a analisar, do ponto de vista teórico, qual seria o equilíbrio necessário entre as demandas individuais e coletivas no âmbito do SUS para o alcance de sua universalidade, esclarecendo os limites do individual e do coletivo dentro do nosso sistema de saúde.

Palavras-chave: Individual; coletivo; universalidade; SUS.

Key-words: Individual; collective; interests; universality; SUS.

\section{Introdução}

O processo de redemocratização do país, que culminou com a promulgação da Constituição Federal de 1988, trouxe consigo mudanças significativas na esfera social. No campo da saúde, pode-se dizer que a criação do Sistema Único de Saúde (SUS) e a elevação do direito à saúde à categoria de direito fundamental criaram as bases para o estabelecimento de uma nova relação entre o cidadão/sociedade e o Estado, pois este passou a ter o dever constitucional de garantir aos indivíduos, titulares do direito fundamental à saúde, acesso universal aos serviços de saúde comtemplados pelo SUS. 
Nesse novo contexto social, onde também emerge a construção de um conjunto de mecanismos com o objetivo de garantir e facilitar o acesso à Justiça, passa-se a observar uma crescente busca individual de efetivação do direito à saúde, seja pela via administrativa, seja pela via judicial, na tentativa de ver materializado o acesso aos serviços e bens que foram garantidos pela nova Constituição. Com efeito, a busca da efetivação do direito à saúde pela via judicial vem sendo objeto de diversos estudos na última década devido ao crescimento no número de demandas judiciais contra o Estado. Este fenômeno, que pode ser observado em estudos realizados em diversos Estados da federação (Chieffi \& Barata, 2009; Borges \& Ugá, 2009; Borges \& Ugá, 2010), denomina-se judicialização das políticas de saúde e caracteriza-se por uma dinâmica na qual o Poder Judiciário se substitui ao Executivo na escolha de fornecer esse ou aquele medicamento/tratamento, sob o fundamento de assegurar a efetivação do direito à saúde, previsto constitucionalmente.

Se de um lado é verdade que a efetivação do direito à saúde de um indivíduo se materializa quando este obtém uma medida judicial que garante acesso ao medicamento/tratamento postulado, de outro, também é verdade que essa efetivação pode estar sendo garantida mediante sacrifício de uma política pública estabelecida na busca pela universalidade e igualdade desse acesso a toda coletividade, condições estas indissociáveis do direito fundamental à saúde, nos moldes estabelecidos pela nova Constituição. O que está implícito no desenho constitucional desse direito social é o dever do Estado de fazer ponderações que possibilitem que a utilização dos bens e serviços disponíveis se dê de forma a garantir universalidade e igualdade de acesso.

Sem deixar de ressalvar as hipóteses que demandam uma intervenção judicial urgente, seja para cuidar de uma questão com especificidades e excepcionalidades não alcançáveis por uma política fundada na universalidade e integralidade, seja para reparar eventuais descumprimentos da própria política estabelecida, o fato é que, em muitas decisões, a complexidade dessa questão é simplificada e tratada de forma individualizada, sem considerar a necessária gestão equitativa dos recursos públicos destinados à saúde.

Recentemente, muitos trabalhos se dedicaram ao estudo dos limites da atuação do Judiciário nas demandas para fornecimento de medicamentos e tratamentos (Borges \& Ugá, 2009; Barroso, 2008). Por isso, o objetivo deste artigo não é o de retomar o tema sob o ponto de vista dos limites da atuação judicial, mas 
sim o de colocar o problema de forma mais ampla, mostrando a existência de conflito de interesses como questão intrínseca à divisão de bens na sociedade, e permitindo, assim, que não só o Judiciário olhe para o problema, mas que, antes disso, gestores e a própria sociedade se tornem cientes da complexidade das questões que giram em torno do acesso e distribuição de serviços de saúde na sociedade.

Dessa forma, levando em consideração os conflitos entre interesses individuais e coletivos em jogo nas demandas individuais para fornecimento de medicamentos/tratamentos, este artigo, a partir do uso de teorias para distribuição de recursos na sociedade, pretende oferecer elementos que contribuam para identificar o ponto de equilíbrio entre esses dois tipos de interesses, sem o qual não se poderá garantir a universalidade no SUS. Primeiro será feita uma breve análise das teorias que justificam a distribuição dos recursos de saúde, categorizando a opção feita pelo Brasil em termos de alocação de recursos e serviços de saúde. A seguir, se explicará o que este trabalho entende por tensão entre o direito individual e coletivo no âmbito da saúde, passando-se, então, ao ponto central do artigo, com o qual se pretende demonstrar quais seriam as ponderações necessárias para obter-se, nesse contexto, uma resolução de conflitos entre interesses individuais e coletivos que reflita os princípios constitucionais da igualdade e universalidade do SUS.

As conclusões do artigo visam contribuir para um redimensionamento da questão envolvendo a efetivação do direito à saúde e, no caso deste artigo, especificamente da questão do fornecimento de medicamentos/tratamentos, lançando argumentos que permitem olhar para o tema com uma "lente de aumento" ou macro visão. Assim, busca-se propor uma releitura do tema, mas não exatamente a propositura de critérios ou parâmetros para atuação judicial, assuntos estes objeto de trabalhos anteriores (Barroso, 2008; Borges \& Ugá, 2009).

\section{Ideologias associadas aos conceitos de individual e coletivo}

Teorias de justiça social ou distributiva são os fundamentos filosóficos que justificam a distribuição de benefícios e encargos dentro da sociedade. Em oposição à ideia de justiça retributiva, que diz respeito às relações privadas e ao que é justo na troca de bens ou no cumprimento de contratos entre indivíduos, sendo normalmente decidida pelos tribunais, a justiça distributiva é a justiça devida pela comunidade a seus membros, incluindo a repartição equitativa das vantagens e encargos comuns, sendo raramente decidida nos tribunais, mas principalmente pelo governo e suas 
respectivas políticas públicas (Black \& Garner, 2009). Diferentes teorias de justiça distributiva irão refletir diferentes princípios morais como a base (ou o significado) para o que é justo e o que distingue essas várias teorias são os princípios usados para dar conteúdo material à ideia de justiça. Embora existam outros princípios e teorias para justificar a distribuição de cuidados de saúde, aqui iremos abordar apenas com os princípios relacionados diretamente com as teorias igualitárias e liberais de justiça. Assim, os princípios materiais de justiça aqui considerados são:

a. Para cada pessoa uma parte igual

b. Para cada pessoa de acordo com a necessidade individual

C. Para cada pessoa de acordo com o esforço individual

d. Para cada pessoa de acordo com a contribuição à sociedade

e. Para cada pessoa de acordo com a capacidade de pagamento

f. Para cada pessoa de acordo com o mérito (ou merecimento)

Considerando-se que a distribuição dos serviços de saúde é essencialmente uma questão política, cada governo invoca um ou mais desses princípios materiais para fins de políticas públicas, aplicando princípios diferentes para diferentes contextos. Veremos abaixo as principais teorias de justiça utilizadas para justificar a distribuição de serviços relacionados à saúde.

\subsection{Teoria da igualdade}

Teorias igualitárias de justiça enfatizam a igualdade de acesso ou igual distribuição de bens sociais como princípio material da justiça. Um critério tradicional e comum usado é o princípio aristotélico de igualdade que prescreve que os iguais devem ser tratados de forma igual e os desiguais podem ser tratados de forma desigual. No entanto, essa ideia básica de igualdade é meramente formal, uma vez que não existe qualquer referência ao que deve ser considerado igual. Assim, formulado deste modo, o princípio carece de substância e, a fim de especificar os motivos relevantes pelos quais as pessoas devem ser tratadas da mesma forma, é necessário fazer referência ao tipo de igualdade em consideração.

O princípio da igualdade material clássico em termos de distribuição de mercadorias corresponde à ideia de que cada um merece uma parte igual. No entanto, uma igualdade extrema na distribuição de recursos, embora desejável, pode ser inviável. Primeiro porque a forma como as sociedades modernas se organizam em termos de estruturas legais, políticas e econômicas não permite uma distribuição 
totalmente igualitária dos recursos, sem implicar também uma violação dos direitos de propriedade individuais. Em segundo lugar, mesmo que a igualdade fosse assim alcançada, a desigualdade provavelmente iria novamente emergir, porque as capacidades, qualidades e desejos das pessoas são diferentes.

No campo da saúde, este tipo de extremo igualitarismo ou "forte igualitarismo", como referido por Olsen (1997), é evitado, pois pode levar a situações absurdas em que um indivíduo saudável, recebe a mesma quantidade de cuidados de uma pessoa com real necessidade de cuidados. Portanto, se o objetivo é obter um resultado igualitário na distribuição de recursos, sem violar os direitos individuais ou conduzir a situações absurdas, outras regras e princípios devem ser aplicados de forma a obter a equalização das diferenças entre os indivíduos. Neste sentido, outra regra usada por igualitaristas é o princípio da igualdade de oportunidades. De acordo com esta regra, a igualdade é alcançada, dando às pessoas a igualdade de acesso a oportunidades na sociedade, ou seja, todos os indivíduos na sociedade com o mesmo talento nativo e ambição devem ter as mesmas perspectivas de sucesso na competição por posições que conferem benefícios especiais e vantagens (Olsen, 1997). ${ }^{1}$ No campo da saúde, o princípio da igualdade de oportunidades vem sendo utilizado calcado nas ideias de autores que sustentam que proteger a saúde é proteger as oportunidades que os indivíduos podem exercer na vida. Assim, a manutenção do funcionamento normal do corpo através de acesso a serviços de saúde contribui para proteger o leque de oportunidades que as pessoas podem razoavelmente exercer na vida. Ainda que a saúde não seja o único fator a afetar o leque de oportunidades abertas às pessoas, a perda de funcionamento ou a morte prematura, causados por problemas de saúde, diminuem claramente a gama de planos de vida das pessoas em dada sociedade (Daniels, 2008).

Outro conceito normalmente utilizado pelos que defendem teorias igualitárias na área da saúde é o de necessidade. Apesar de necessidade ser um conceito amplo e não existir ainda convergência na sua definição, dois aspectos são tidos como importantes para caracterizar a necessidade no campo da saúde. O primeiro deles, normalmente utilizados por médicos, refere-se ao estado de saúde do indivíduo no pré-tratamento, sendo certo que a situação caracterizada com mais problemas de

\footnotetext{
${ }^{1} \mathrm{O}$ princípio da igualdade de oportunidades foi divulgado no final do século XX pela teoria de justiça desenvolvida por John Rawls. Embora um filósofo da tradição liberal, a distribuição de bens sociais proposta pela teoria de Rawls é associada ao igualitarismo (Rawls, 1999).
} 
saúde irá equivaler a uma maior necessidade de cuidados. Já o segundo refere-se à definição adotada pela maioria dos economistas de saúde, que sustenta que a capacidade do indivíduo de se beneficiar de cuidados de saúde determina o tamanho de sua necessidade (Mossialos \& Oliver, 2004).

Desta forma, reunindo o princípio básico de igualdade e os conceitos de igualdade de oportunidades e de necessidade, teremos, então, que a justiça igualitária na distribuição dos serviços e recursos de saúde resultará em igual acesso aos serviços de saúde para pessoas com necessidades iguais de saúde, ou seja, acesso ao mesmo tipo de serviços de saúde no que diz respeito à satisfação das suas necessidades.

\subsection{Teoria liberal}

Originalmente calcada nas ideias propostas por Adam Smith e em teorias do laissez-faire, a teoria liberal funda seu discurso em torno do indivíduo e dos direitos individuais, enfatizando a liberdade pessoal e de escolha como valores básicos dominantes. A realidade social é traçada pela primazia do indivíduo, que é um ser racional capaz de ser o melhor juiz de seu interesse. Assim, uma sociedade justa na ótica liberal não é aquela que busca promover o bem geral ou uma distribuição igualitária, mas sim aquela que promove os direitos e as liberdades individuais e que protege seus indivíduos de qualquer tipo de intervenção do Estado que possa afetar as liberdades e escolhas dos cidadãos.

A perspectiva liberal, nos dias de hoje, se manifesta a partir da proteção à dignidade da pessoa humana e pela valorização dos direitos fundamentais negativos que limitam a atuação do Estado em nome da liberdade materializada pela livre iniciativa e fruição dos direitos individuais.

Quando aplicada à distribuição dos serviços de saúde na sociedade, a perspectiva liberal enxerga as desigualdades nas condições de acesso aos serviços como um mero reflexo das diferentes escolhas e diferentes contribuições feitas pelos indivíduos e sua superação dependerá do esforço individual e não de uma ação promovida pelas instituições políticas, cuja finalidade deve se limitar a garantir a autonomia e a defesa dos direitos individuais.

$\mathrm{Na}$ prática, os sistemas de saúde que usam como base princípios da teoria liberal são aqueles onde o mercado se sobrepõe ao Estado na provisão de serviços. Nestes sistemas, o princípio material implícito na distribuição dos serviços é a 
capacidade de pagamento. O Estado não desempenha um papel importante na distribuição de bens e serviços de saúde e a liberdade de escolha na compra de serviços de saúde pelos indivíduos reflete a lógica da liberdade econômica predominante. Um exemplo de sistema de saúde baseado nos princípios liberais é o sistema americano, no qual o poder de compra do indivíduo é o que define o tipo de serviço de saúde/cobertura ao qual ele terá acesso. Mesmo com a recente reforma do sistema de saúde americano, ${ }^{2}$ que buscou, entre outras coisas, reduzir o número de americanos desprovidos de cobertura de saúde, a lógica liberal do sistema não foi alterada, permanecendo, portanto, as desigualdades resultantes do diferente poder de compra dos indivíduos.

\subsection{Comunitarismo}

Em oposição ao individualismo difundido pelo liberalismo, que é a política de direitos, o comunitarismo surge na década de 80 e procura colocar a ética longe dos direitos individuais, criando uma teoria que enfatiza a moral baseada na cultura, na comunidade e suas relações específicas, e defendendo que as liberdades individuais só podem ser usufruídas quando fundadas em normas compartilhadas pela comunidade.

Dessa forma, sob o olhar do comunitarismo, a individualidade pode ser ampliada como resultado da experiência social e só é sustentável pelo fato de pertencermos a uma comunidade (Selznick, 2002). Os vínculos comunitários se colocam como valor central e a construção social como norteador de soluções para os dilemas morais inerentes a qualquer contexto social comunitário.

Em termos de justiça social, a ideologia comunitarista promove uma distribuição equitativa de recursos, buscando equacionar a distribuição de recursos e bens socialmente relevantes. Especificamente em relação aos serviços de saúde, uma visão comunitária sugere que, em virtude da condição de membro de certa sociedade, os indivíduos devem se preocupar com a saúde dos outros. Isto se reflete, por exemplo, no principio da solidariedade que prevê políticas públicas de subsídios cruzados dos mais ricos para os mais pobres e dos indivíduos saudáveis para os doentes.

\footnotetext{
${ }^{2}$ Patient Protection and Affordable Care Act ou, simplesmete, Obamacare. Detalhes sobre a reforma estão disponíveis em http://housedocs.house.gov/energycommerce/ppacacon.pdf [Acesso em 14.09.2013]. Sobre a decisao da Suprema Corte Americana que limitou os efeitos da reforma, ver http://www.supremecourt.gov/opinions/11pdf/11-393c3a2.pdf [Acesso em 14.10.2013].
} 
A partir da análise das teorias de distribuição acimas expostas, pode-se concluir que a criação e o desenvolvimento do SUS têm por base princípios da teoria igualitária e do comunitarismo. Isto fica evidente a partir da leitura do artigo 196 da Constituição Federal que fala expressamente em "acesso universal e igualitário" aos serviços de saúde. Tais princípios são novamente reiterados na legislação infraconstitucional, sendo certo que na Lei $n^{\circ} 8.08$ 0/90 encontramos menção a tais princípios, seja nas disposições gerais (artigo 29), seja no dispositivo que explicita os princípios e diretrizes do SUS (art. 79.

Portanto, ainda que exista no nosso sistema de saúde considerável participação do mercado privado na provisão de serviços de saúde, caracterizado pelo chamado sistema suplementar, a opção do Brasil com a criação do SUS foi a de oferecer um sistema público e universal de saúde, baseado em princípios como o da igualdade e solidariedade. Assim, no âmbito do SUS, os direitos de natureza individual deverão ser sempre ponderados em relação ao direito da coletividade e submetidos a um teste de proporcionalidade, pois, do contrário, corre-se o risco de fugirmos ao alcance dos objetivos e princípios de um sistema de saúde universal e igualitário.

\section{Entendendo a tensão entre o direito individual e coletivo no âmbito da saúde}

Em nossa Constituição, a tensão entre o liberalismo e comunitarismo está expressa na coexistência de um conjunto de princípios e instituições estabelecidas, de um lado, na perspectiva de garantir a dignidade da pessoa humana e, de outro, pelo rol de direitos sociais - declarados fundamentais - cuja garantia e efetivação são impostos ao encargo do Estado.

Reconhecendo e acolhendo essa tensão, a Constituição acaba por devolver à sociedade e suas instituições o ônus de solucionar os conflitos gerados entre direitos individuais e direitos sociais, agravados pela secular dificuldade de superação da escassez dos recursos demandados para garantir a efetivação de direitos que têm repercussão tanto na perspectiva da dignidade da pessoa humana quanto na perspectiva dos direitos considerados fundamentais pela comunidade - como é o caso do direito à saúde.

No âmbito da saúde pública, a confusão entre esses dois níveis - individual e coletivo - quando da postulação individual desse direito social, não nos parece estar contribuindo para reduzir essa tensão e, em alguma medida, pode estar dificultando a 
Anais dos III Congresso Iberoamericano de Direito Sanitário / II Congresso Brasileiro de Direito Sanitário efetivação do direito à saúde com garantia de acesso orientada pela equidade e universalidade, como preconizado por nossa Constituição. Como superar os dilemas e apelos gerados diante de um caso individual que envolve questões de vida e morte? Esse é o desafio.

O primeiro desafio que se impõe é entender que o direito subjetivo à saúde, no âmbito da iniciativa privada, não se confunde e nem se manifesta da mesma forma quando se trata de reconhecer esse direito em relação ao dever do Estado de garantir a saúde. Quando uma demanda é ajuizada para obter a garantia de acesso a um medicamento/tratamento negado por uma operadora de plano privado de assistência à saúde, estamos diante de uma demanda individual, reconhecida juridicamente como um direito subjetivo privado, onde os valores fundamentais associados ao direito à saúde foram preservados no âmbito da legislação aplicável à relação entre o consumidor e a operadora do plano de saúde - no caso brasileiro, a Lei no 9.656/98 e o Código de Proteção e Defesa do Consumidor (Lei 8.078/90). Nesses casos, a intervenção judicial deverá - ou deveria - se dar no sentido de fazer garantir as normas de ordem pública estabelecidas no diploma legal ou nas disposições contratuais subsidiárias.

Se essa formulação do problema pode ser considerada simplificadora na perspectiva do direito individual e esfera privada, no âmbito do direito subjetivo público, onde se impõe ao Estado o dever de garantir acesso aos bens e serviços de saúde com equidade e universalidade, ela, com certeza, se mostrará insuficiente e inadequada. Enquanto o bem garantido pelo direito subjetivo privado à saúde se materializa no bem e/ou serviço de saúde demandado pelo consumidor microalocação de recurso, o direito subjetivo público à saúde se materializa pela formulação e execução de políticas públicas que garantam que o acesso aos bens e serviços, escassos e limitados, de saúde se dê de forma equânime e universal macroalocação de recursos. Esta interpretação se coaduna com a redação do paragrafo $1^{\circ}$ do artigo $2^{\circ}$ da Lei $n^{\circ} 8.080 / 90$, que d ispõe que "O dever do Estado de garantir a saúde consiste na formulação e execução de políticas econômicas e sociais que visem à redução de riscos de doenças e de outros agravos e no estabelecimento de condições que assegurem acesso universal e igualitário às ações e aos serviços para a sua promoção, proteção e recuperação."

$\mathrm{Na}$ perspectiva do direito subjetivo público, ao contrário do que ocorre no âmbito privado, o titular desse direito deixa de ser um indivíduo e a obrigação do 
Anais dos III Congresso Iberoamericano de Direito Sanitário / II Congresso Brasileiro de Direito Sanitário

Estado deixa de ser a de garantir acesso e cobertura a um determinado tratamento/medicamento. Nos termos estabelecidos pela Constituição Federal de 1988, o direito individual à saúde não pode ser dissociado do direito da coletividade saúde como "direito de todos" - e de seu contexto social, e o dever do Estado é o de formular e executar "políticas sociais e econômicas que visem à redução do risco de doença e de outros agravos e ao acesso universal e igualitário às ações e serviços para sua promoção, proteção e recuperação" - e não o de garantir acesso a tratamentos/medicamentos específicos e dissociados dessa política.

Assim, quando o Judiciário obriga o Estado a fornecer determinado medicamento/tratamento a um único indivíduo, sem levar em consideração a política pública estabelecida ou qualquer outro critério distributivo dos recursos existentes, ele, em verdade, se impõe uma "escolha de Sofia", garantindo a sobrevivência de um indivíduo em detrimento de muitos outros, não contribuindo em nada para que o Estado cumpra seu dever constitucional de implementar políticas públicas que garantam integralidade, igualdade e universalidade de acesso.

\section{Princípios que contribuem para uma solução adequada da tensão entre o individual e o coletivo}

Um adequado dimensionamento da questão envolvendo a efetivação do direito à saúde é o segundo desafio que se impõe enfrentar. Ao pensarmos em saúde no âmbito do SUS, é necessário se ter presente que não se está examinando um direito individual a partir de regras que prescrevem determinados comportamentos a serem observados pelas partes envolvidas, onde se pode encontrar uma solução específica para cada caso concreto. O ponto de partida para análise de questões que envolvem um direito social de natureza coletiva são os princípios e estes não nos conduzem a soluções concretas, mas nos instrumentalizam para a necessária ponderação de valores envolvidos quando a questão se trata de realizar a justiça distributiva na alocação de escassos bens e recursos de saúde.

Essa ponderação se impõe porque os direitos individuais e os direitos coletivos convivem lado a lado no texto constitucional, legitimando e limitando o exercício do poder político pelo Estado. A dimensão individual se evidencia pelo fato de o homem ser colocado no epicentro do ordenamento jurídico e a ele se relacionar todo o elenco de direitos fundamentais afirmados e protegidos pela Constituição. A dimensão coletiva se evidencia toda vez que o próprio constituinte reconhece a preponderância 
Anais dos III Congresso Iberoamericano de Direito Sanitário / II Congresso Brasileiro de Direito Sanitário

de direitos de natureza transindividual, permitindo a limitação de direitos individuais em prol da tutela de interesses difusos.

No caso da saúde a ser garantida pelo Estado, nos parece evidente a preponderância dos interesses coletivos em detrimento de direitos e interesses individuais. Reconhecendo que agir de acordo com a lei é agir de acordo com sua finalidade, o dever que se impõe ao seu intérprete é o de dar materialidade ao fim por ela preconizado que, por sua vez, se identifica e se confunde com o interesse público envolvido. Assim, o desafio de quem aplica a lei é o de identificar e realizar o interesse público, seja ele equiparado a um legítimo direito individual, seja ele equiparado a um direito coletivo.

Para enfrentar a espinhosa questão de conceituar o interesse público nos valemos das lições de Mello que o define como "o interesse resultante do conjunto dos interesses que os indivíduos pessoalmente têm quando considerados em sua qualidade de membros da Sociedade e pelo simples fato de o serem" (Mello, 2007). Dessa definição, o autor extrai conclusões importantes que permitem superar a falsa oposição existente entre o interesse público e os interesses individuais ou a mera identificação do interesse público como a soma de interesses individuais.

O interesse público, no sentido proposto, é o que Mello chama de faceta coletiva ou dimensão pública dos interesses individuais, permitindo que se vislumbre que, de um lado, o particular também tem direito subjetivo à defesa dos interesses consagrados como públicos na medida em que estes também traduzem uma dimensão de seus próprios interesses.

A percepção de que ao se proteger o interesse coletivo também se está protegendo o interesse individual, no caso da saúde, pode representar um grande avanço na garantia da igualdade e universalidade de acesso ao sistema de saúde pública no Brasil. A ponderação que cabia ser feita entre o direito individual e o coletivo nessa matéria já foi superada pela Constituição que indicou, de forma clara, que o interesse público, no caso da garantia desse direito, se confunde com o interesse coletivo, pois o acesso a ser garantido pelo Estado deve se dar a todos os indivíduos de forma igualitária e universal. Ao legislador ordinário e ao aplicador da lei - Executivo ou Judiciário - cumpre dar materialidade à realização desse direito mediante a formulação e implementação de políticas públicas que promovam justiça distributiva no âmbito da saúde. 
Reconhecendo-se que o titular do direito à saúde é a coletividade, e que os recursos disponíveis para promover e garantir a saúde são - e provavelmente sempre serão - escassos, os dilemas suscitados por casos individuais que chegam ao Judiciário, matizados com a dramaticidade inerente a todo caso que envolve vida e morte, como mencionamos acima, só podem ser enfrentados se analisados a partir de princípios como o da legalidade, razoabilidade e proporcionalidade.

Dentre esses, nos parece especialmente adequado para conduzir a uma solução justa na perspectiva distributiva de recursos escassos, o postulado da proporcionalidade, pelo qual, como nos ensina Ávila (2005), a decisão no caso concreto deverá se mostrar adequada, necessária e proporcional em sentido estrito. Este autor prossegue, indicando que uma determinada decisão é adequada quando ela se presta a atingir o fim almejado; é necessária quando é capaz de alcançar esse fim sem ou com a menor imposição de sacrifício aos direitos fundamentais envolvidos e é proporcional quando o valor da promoção desse fim não for proporcional ao desvalor da restrição ao universo de direitos fundamentais afetados.

Nesse mesmo sentido, trazemos a lição de Justen Filho (2010) para quem adequação deve significar o vínculo de causalidade lógica entre a providência limitativa adotada e o fim concreto que a justifica; necessidade é o que impõe ao Administrador a obrigação de adotar a providência dotada de menor potencial de restritividade possível dentre as diversas opções que se revelam como adequadas; e compatibilidade com a Constituição é o que impede a consagração de providências restritivas que suprimam ou ofendam valores ou direitos fundamentais, consagrados como intangíveis.

Do conteúdo atribuído a esse princípio, podemos inferir ser dever do aplicador da lei atuar nos limites necessários e suficientes à realização da finalidade almejada pela norma - que, no caso da saúde, é a garantia de acesso universal e igualitário. Pelo manejo deste princípio é que se pode garantir que o direito de todos à saúde só será onerado por um interesse individual na exata medida em que a materialização do interesse público o exigir. Sua importância é de tal ordem que não seria equivocado afirmar que é na busca da justa proporção que a norma mais depende do aplicador para se realizar em seu sentido ótimo, pois o excesso cometido para garantir a realização de um interesse individual representa agravo indevido ao direito de acesso de todos os demais. 


\section{Conclusões}

Os argumentos trazidos por este artigo visaram mostrar que a justa distribuição de recursos de saúde na sociedade depende da opção sobre a qual se fundam os ideais de justiça de dada sociedade. Assim, de acordo com a teoria igualitária, a justa distribuição dos serviços e recursos de saúde resultará em igual acesso aos serviços de saúde para pessoas com necessidades iguais de saúde, ou seja, acesso ao mesmo tipo de serviços de saúde no que diz respeito à satisfação das suas necessidades. Por outro lado, a teoria liberal deixa a justa distribuição a cargo da capacidade de escolha e compra do indivíduo.

Apesar de atualmente não existir uma separação estrita entre esses dois modelos, e de muitos sistemas igualitários fazerem uso de mecanismos liberais, o que ainda predomina nos sistemas que oferecem serviços públicos universais, são políticas fundadas na teoria da igualdade, e, portanto, equidade no acesso aos serviços de saúde para pessoas com necessidades iguais de saúde, ou seja, acesso ao mesmo tipo de serviços de saúde no que diz respeito à satisfação das suas necessidades.

Apesar da considerável participação do mercado privado na provisão de serviços de saúde, a opção do Brasil com a criação do SUS foi a de oferecer um sistema público de saúde, de acesso universal e igualitário, ou seja, baseado nos ideias da teoria igualitária e do comunitarismo, que utilizam a equidade e a solidariedade como princípios fundadores.

Nessa ótica, uma exacerbação de direitos individuais - neste artigo exemplificada através das ações judiciais individuais para obtenção de medicamentos e tratamentos no âmbito do SUS - sem a necessária ponderação dos interesses coletivos em questão, pode representar verdadeira violação aos ideais igualitários do sistema.

O entendimento da tensão existente entre o nível individual e o coletivo dentro do SUS auxilia na compreensão e redimensionamento da questão, mostrando que decisões que reconhecem apenas a esfera individual (da efetivação) do direito à saúde, simplificam a questão, sem considerar o interesse coletivo e a necessária gestão equitativa dos recursos públicos destinados à saúde.

A busca pela universalidade e equidade do SUS passa necessariamente pela ponderação entre os interesses individuais e os coletivos, sob pena de estarmos nos afastando dos ideais e princípios nos quais se baseiam o sistema. 
A nossa Constituição oferece ferramentas para lidar com a tensão e realizar a necessária ponderação, através dos princípios que orientam a prática da administração pública. O princípio da supremacia do interesse público e o reconhecimento de que este interesse, no âmbito da saúde, enquanto direito social fundamental, se confunde com o interesse coletivo, nos permite indicar que a proteção do direito individual deverá se dar, não pela garantia de seu interesse imediato, e sim garantia de existência de políticas públicas que garantam acesso igualitário e universal aos bens e serviços de saúde - revelando a faceta pública e coletiva do interesse individual.

Partindo dessa formulação, a busca pela solução de eventual conflito entre interesses individuais e coletivos deverá se fundar nas ponderações norteadas pelos princípios da razoabilidade e proporcionalidade, por razoável entendendo-se aquilo que é conforme à razão, ao Direito e à equidade. Assim, a eleição do princípio da razoabilidade como condicionante do agir do Estado significa dizer que as decisões devem guardar congruência com a norma que se está a aplicar, produzindo um resultado coerente e harmonioso com a finalidade por ela almejada. Este é um ônus do aplicador da lei: eleger os meios necessários para alcançar os fins perseguidos pela lei. E por proporcional entendendo-se o atuar dentro dos limites necessários e suficientes à realização da finalidade almejada pela norma.

A realização de direitos fundamentais não será garantida pelas decisões fundadas na mera invocação de cláusulas abstratas como a de "garantia à saúde" ou de "interesse público". Impõe-se ao Estado, por outro lado, o dever de demonstrar a realização da justa distribuição de recursos envolvidos na promoção e efetivação de direitos consagrados como fundamentais pela sociedade.

\section{Referências}

ÁVILA, H. Teoria dos princípios: da definição à aplicação dos princípios jurídicos, 4ạ . ed.. São Paulo : Malheiros Editores, 2005.

BARROSO, L. R. Da falta de efetividade à judicialização excessiva: direito à saúde, fornecimento gratuito de medicamentos e parâmetros para a atuação judicial. Rio de Janeiro. Trabalho desenvolvido por solicitação da Procuradoria-Geral do Estado do Rio de Janeiro, 2008. Disponível em http://pfdc.pgr.mpf.mp.br/atuacao-e-conteudosde-apoio/publicacoes/saude/Saude - judicializacao - Luis Roberto Barroso.pdf Acesso em 26 ago.2013.

BLACK, H. C. \& GARNER, B. A. Black's Law Dictionary. St. Paul : Thomson Reuters, 2009. 
Anais dos III Congresso Iberoamericano de Direito Sanitário / II Congresso Brasileiro de Direito Sanitário

BORGES, D. D. C. L. \& UGA, M. A. D. As ações individuais para o fornecimento de medicamentos no âmbito do sus: características dos conflitos e limites para a atuação judicial. Revista de Direito Sanitário,10(1):13-38, mar./jul. 2009.

BORGES, D. D. C. L. \& UGÁ, M. A. D. Conflitos e impasses da judicialização na obtenção de medicamentos: as decisões de 1a instância nas ações individuais contra o Estado do Rio de Janeiro, Brasil, em 2005. Cadernos de Saúde Pública, 26:59-69, 2010.

CHIEFFI, A. L. \& BARATA, R. B. Judicialização da política pública de assistência farmacêutica e eqüidade. Cadernos de Saúde Pública, 25:1839-1849, 2009.

DANIELS, N. Just health: meeting health needs fairly, Cambridge : New York, Cambridge University Press, 2008.

JUSTEN FILHO, M. Curso de Direito Administrativo. 5ํㅗㄹ ed. São Paulo : Saraiva, 2010.

MELLO, C. A. B. Curso de Direito Administrativo. 22 $2^{\underline{a}}$ ed. São Paulo : Malheiros Editores, 2007.

MOSSIALOS, E. \& OLIVER, A. Equity of access to health care: outlining the foundations for actions. Journal of Epidemiology and Community Health, 58: 655-58, 2004.

OLSEN, J. A. Theories of justice and their implications for priority setting in health care. Journal of Health Economics, 16(6):625-639, 1997.

RAWLS, J. A theory of justice. Cambridge : Belknap Press of Harvard University Press, 1999.

SELZNICK, P. The Communitarian Persuasion. Baltimore and London : Johns Hopkins University Press, 2002. 